Article

\title{
Continuous Separation of Light Olefin/Paraffin Mixtures on ZIF-4 by Pressure Swing Adsorption and Membrane Permeation
}

\author{
Maximilian Hovestadt ${ }^{1}$ (D), Sebastian Friebe ${ }^{2}$, Lailah Helmich ${ }^{2}$, Marcus Lange ${ }^{3}$, Jens Möllmer ${ }^{3}$, \\ Roger Gläser ${ }^{3}{ }^{(1)}$, Alexander Mundstock ${ }^{2}$ and Martin Hartmann ${ }^{1, *}$ \\ 1 Erlangen Catalysis Resource Center (ECRC), Friedrich-Alexander-Universität Erlangen-Nürnberg (FAU), \\ Egerlandstr. 3, 91058 Erlangen, Germany; maximilian.hovestadt@fau.de \\ 2 Institute of Physical Chemistry and Electrochemistry, Leibniz University Hannover, Callinstrasse 3A, \\ 30167 Hannover, Germany; sebastian.friebe@pci.uni-hannover.de (S.F.); 1.helmich@isfh.de (L.H.); \\ alexander.mundstock@pci.uni-hannover.de (A.M.) \\ 3 Institut für Nichtklassische Chemie e.V. (INC), Permoserstraße 15, 04318 Leipzig, Germany; \\ lange@inc.uni-leipzig.de (M.L.); moellmer@inc.uni-leipzig.de (J.M.); roger.glaeser@uni-leipzig.de (R.G.) \\ * Correspondence: martin.hartmann@fau.de; Tel.: +49-9131-8528792
}

Received: 23 February 2018; Accepted: 5 April 2018; Published: 11 April 2018

\begin{abstract}
In this study, two zeolitic imidazolate frameworks (ZIFs) called ZIF-4 and ZIF-zni (zni is the network topology) were characterized by sorption studies regarding their paraffin/olefin separation potential. In particular, equilibrated pure and mixed gas adsorption isotherms of ethane and ethene were recorded at $293 \mathrm{~K}$ up to $3 \mathrm{MPa}$. ZIF-4 exhibits selectivities for ethane in the range of 1.5-3, which is promising for continuous pressure swing adsorption (PSA). ZIF-4 shows high cycle stability with promising separation potential regarding ethane, which results in purification of the more industrial desired olefin. Furthermore, both ZIF materials were implemented in Matrimid to prepare a mixed matrix membrane (MMM) and were used in the continuous separation of a propane/propene mixture. The separation performance of the neat polymer is drastically increased after embedding porous ZIF-4 crystals in the Matrimid matrix, especially at higher feed pressures ( $3-5 \mathrm{barg}$ ). Due to the smaller kinetic diameter of the olefin, the permeability is higher compared to the paraffin.
\end{abstract}

Keywords: ZIF-4; olefin/paraffin separation; pressure swing adsorption (PSA); membrane permeation

\section{Introduction}

Several studies have shown the separation capabilities of porous materials for olefin/paraffin separation as a potential green alternative to energy-intensive low temperature distillation [1-3]. In particular, pressure swing adsorption and membrane permeation are industrially proven alternative separation processes, but are up till now not used in olefin/paraffin separation due to a lack of selective adsorbents or membranes. An auspicious adsorbent candidate is ZIF-4 [4], which has shown a higher adsorption capacity for paraffin compared to olefin in isotherm measurements as well as a good separation performance in breakthrough experiments for different feed compositions. Thus, ZIF-4 differs from well-known conventional adsorbents such as zeolites [5] and metal-organic frameworks with open metal sites like $\mathrm{CPO}-27$ and $\mathrm{Cu}_{2}(\mathrm{BTC})_{3}$ [6-8]. These materials show stronger interaction with olefin, and the loading is based on the effect described by Dewar, Chatt, and Duncanson $[9,10]$. A selectivity analogous to ZIF-4 has in principle been reported for similar adsorbents namely ZIF-7 [11], ZIF-8 [7], ZIF-71 [2] FIR-51 [12], UTSA-10 [13], and PCN-250 [14] and several activated carbons [15-17]. However, these materials are more expensive in preparation, exhibit an unfavorable separation potential, or are not well studied. 
ZIF-4 belongs to the group of so-called zeolitic imidazolate frameworks (ZIF) that consists of zinc metal centers connected to imidazole-based organic linker molecules. Besides ZIF-4, which possesses cag topology, different polymorphs such as ZIF-zni (zni topology), ZIF-1 (BCT), ZIF-3 (DFT), ZIF-6 (GIS), and ZIF-10 (MER) are known [18]. From this group, ZIF-4 possesses the smallest cage opening (ca. $0.2 \mathrm{~nm}$ as determined from its crystal structure [18]), while ZIF-zni is supposed to be the densest polymorphs within this combination of metal atoms and linker molecules. Adsorption isotherms of pure gases are typically recorded to render the separation potential of porous materials. While pure gas isotherm measurements only imply an adsorptive selectivity, it is necessary to measure mixed gas isotherms to be able to determine the separation potential by adsorption for dynamic separation processes.

To improve the separation performance in breakthrough and pressure swing adsorption (PSA) experiments, high-pressure isotherms are beneficial to determine the optimal sorption conditions for dynamic separation. Additionally, a volumetric set-up combined with a gravimetric system allowed us to determine sorption equilibria of binary gas mixtures of ethane and ethene. From these results, we were able to derive the equilibrium selectivity for this sorption process.

To prove the separation concept with porous materials, continuous separation experiments are indispensable. There are three different instrument-based solutions: the PSA setup, used, e.g., for air separation [19] and hydrogen purification [20], simulated moving bed (SMB) technology, which was tested with zeolite 13X [21], and membrane-assisted separation, which is used for several industry-relevant separation problems such as $\mathrm{CO}_{2}$ capture [22,23], hydrocarbon gas separation [24,25], and dewatering [26]. The advantage of these technologies is the ambient separation temperature and the related low energy costs. The PSA technology is well established for separating continuous feed mixtures with adsorber columns filled with porous adsorbents. At least two filled columns are applied alternatively to continuously separate a certain feed mixture. Thereby, the separation is possible due to kinetic effects, differences in adsorption equilibrium, or molecular sieving.

This also applies to membrane-based technologies. The process can be described as a transport across the membrane due to a concentration gradient (Fick's law). However, for dense (polymer-based) membranes, which transport gas molecules by the solution-diffusion mechanism, the amount adsorbed depends strongly on the ability of the gas to be dissolved in the polymeric matrix, which can be approximated via the condensability of the gas or its molecular size [27]. Mixed matrix membranes (MMMs) are a special case. They consist of a polymer matrix with dispersed fillers (e.g., carbon, ZIFs, and silica). The polymer ensures favorable mechanical properties (flexibility, long-term stability, and reproducibility), while the incorporated additives can either behave as a transport barrier or as separation-active filler. MMMs provide all positive features of both materials and often show increased separation capabilities in comparison to the single materials [28-31].

In this study, the continuous separation potential of ZIF-4 powder for an ethane/ethene gas mixture was tested in a commercial PSA setup. To find the best separation conditions for the continuous setup, high-pressure and mixed adsorption isotherms for ethane and ethene have been recorded. In addition, MMMs with implemented ZIF-4 and ZIF-zni crystals were investigated with respect to their separation potential for propane/propene gas mixtures, which could not be separated using ZIF-4 powder as described in our previous paper [4].

\section{Results and Discussion}

\subsection{Isotherms}

The equilibrium adsorption isotherms of pure ethane and ethene at $20^{\circ} \mathrm{C}$ up to $3 \mathrm{MPa}$ (Figure 1) show the typical type I behavior according the IUPAC isotherm classification [32]. The experimental data were fitted with the adsorption isotherm model of Toth, which describes the experimental data with sufficient accuracy over a wide pressure range. 


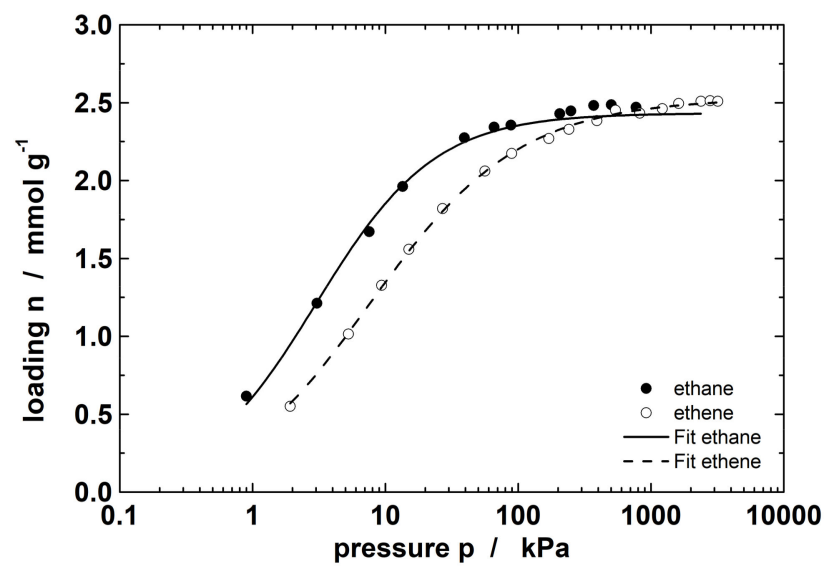

Figure 1. Adsorption isotherm of ethane and ethene at $20^{\circ} \mathrm{C}$ on ZIF-4 and the respective fit data from the Toth model.

The presented data show a higher sorption capacity for ethane compared to ethene at lower pressure $(0-300 \mathrm{kPa})$. However, at higher pressure $(300-3000 \mathrm{kPa})$, the loading of ethane reaches a saturation plateau while the loading of ethene still increases. This leads to a decrease in selectivity until a slightly higher loading is found for ethene compared to ethane (for $p>500 \mathrm{kPa}$ ). This implies that the best separation results should be obtained up to a pressure of about $100 \mathrm{kPa}$. To demonstrate the ideal behavior for this mixture, we measured the mixed gas adsorption isotherm (Figure 2).

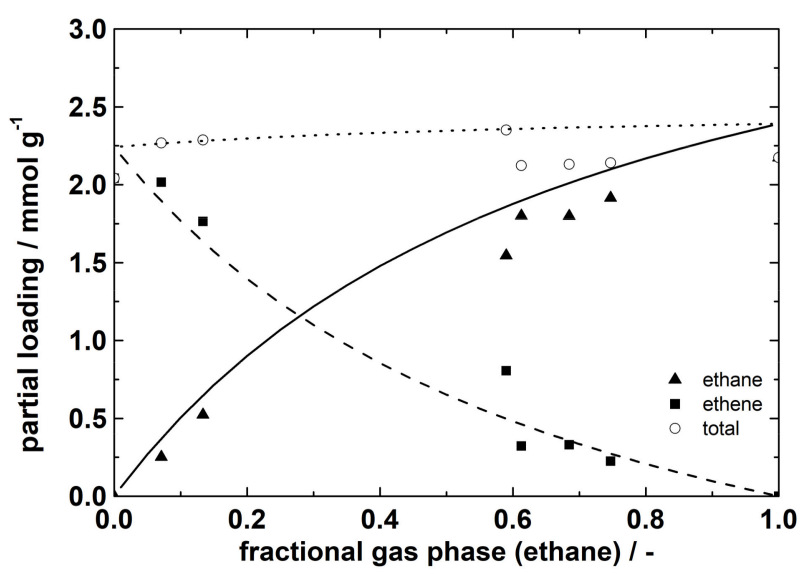

Figure 2. Mixed adsorption equilibria for ethane/ethene at a total pressure of $100 \mathrm{kPa}$ and $20{ }^{\circ} \mathrm{C}$ on ZIF-4. Lines demonstrate calculated data from ideal adsorbed solution theory (IAST) based on Toth fit from single gas isotherms.

The plot shows the partial loadings of ethane and ethene as a function of the fractional amount of ethane in the gas phase. The experimental values are compared to the calculated ones from ideal adsorbed solution theory (IAST) based on the Toth fits from single gas isotherms. Because of the good agreement, ideal adsorption behavior can be assumed. From the plot, partial loadings for a certain gas phase fraction can be obtained. In Figure 3, additionally the fractional loading is plotted versus the fractional gas phase of ethane. Both plots illustrate the preferential sorption of ethane on ZIF-4 under the prevailing equilibrium conditions.

In the literature, mixture data of ethane and ethene on common adsorbents like activated carbons (BPL [33], Nuxit-Al [34]) or zeolites (13X [35]) under comparable conditions are reported. In agreement with our study, activated carbons also show an enrichment for ethane. In detail, AC BPL shows an equilibrium selectivity $\alpha=1.24$ regarding ethane at $301 \mathrm{~K}$ and $138 \mathrm{kPa}$ for an ethane/ethene mixture 
with a ratio of $28 / 72 \%$. The AC Nuxit-Al has a nearly constant selectivity of $\alpha=1.49-1.56$ over the entire partial pressure range of ethane at $293 \mathrm{~K}$ and $101 \mathrm{kPa}$. The experimentally observed ethane selectivities for ZIF-4 range from 1.5 to 3, which is higher than the values reported for active carbons. In contrast, zeolites typically exhibit a preferential sorption for ethene as a consequence of favorable adsorption sites for unsaturated hydrocarbons [4]. Kaul et al. [35] reported selectivities of $\alpha=4.7-7.4$ for the sorption of ethene over ethane on zeolite $13 \mathrm{X}$ at $323 \mathrm{~K}$ and $138 \mathrm{kPa}$. Thus, ZIF-4 appears to be a promising adsorbent resulting in a higher retention of ethane for PSA experiments aiming at the continuous separation of olefin/paraffin mixtures. The preferred adsorption of ethane in the absence of strong adsorption sites is triggered by the different critical temperatures of the gases. Sakurovs et al. [36] already showed higher volumetric loadings different gases on coals with increasing critical temperatures. The backdrop of this phenomenon is a faster condensation of a gas as a consequence of its higher boiling point that increases with higher critical temperature. Finally, gas adsorbs more easily with faster condensation [37]. This leads to a stronger adsorption of the paraffin compared to olefin. This behavior changes when the olefin shows stronger interaction with specific sorption sites in a porous adsorbent such as zeolites.

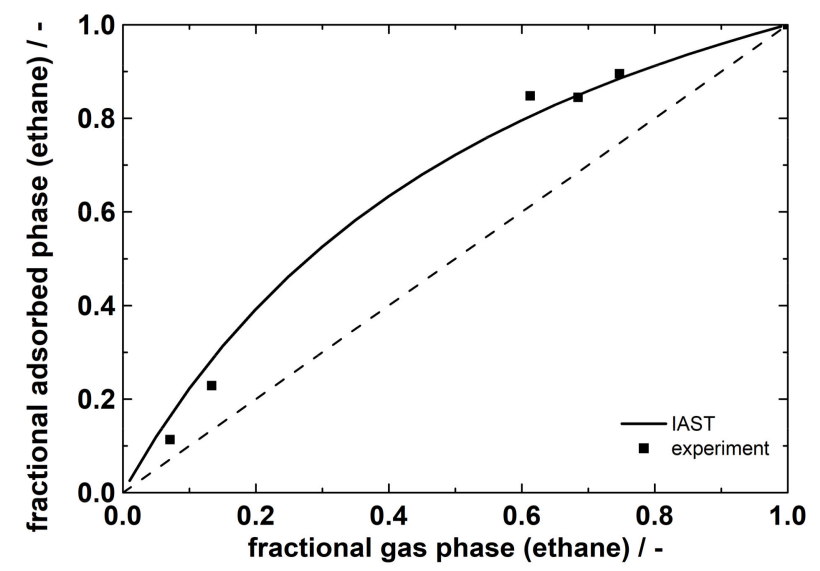

Figure 3. Mixed adsorption equilibria at $20^{\circ} \mathrm{C}$ in ZIF-4 for ethane/ethene at a total pressure of $100 \mathrm{kPa}$.

Lines: calculated data by IAST (using Toth).

\subsection{Continuous Separation of Ethane/Ethene}

The continuous separation of an equimolar ethane/ethene mixture with ZIF-4 powder in an PSA setup at $20^{\circ} \mathrm{C}$ and ambient pressure is displayed in Figure 4.

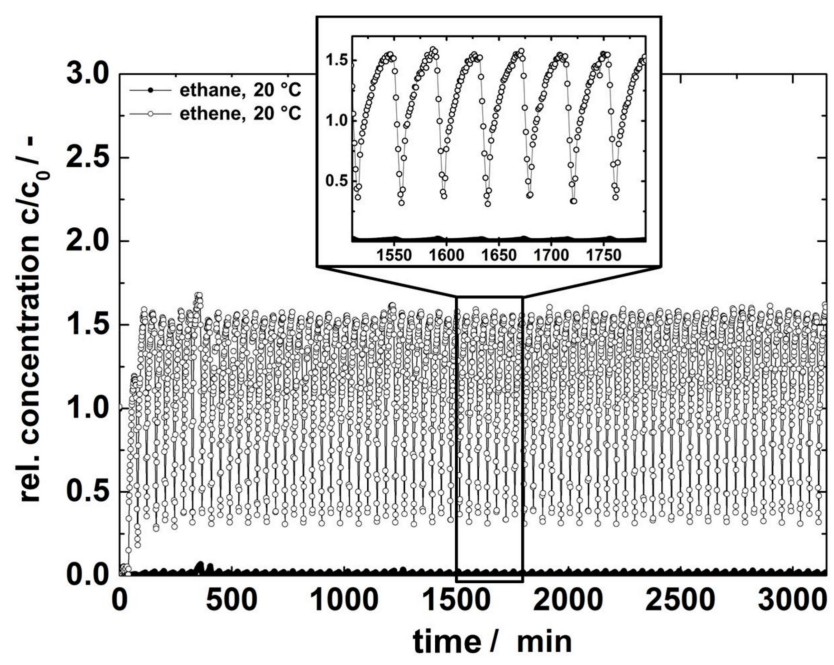

Figure 4. Continuous separation of an equimolar ethane/ethene mixture at ambient pressure and $20^{\circ} \mathrm{C}$. 
The graph shows the relative concentration of ethane and ethene at the outlet of the PSA setup as a function of the retention time. High broad peaks of ethene (open cycles) with low amounts of ethane (closed cycles) are displayed. For clarity, all data points are connected and a section of the complete measurements is added (cf. Figure 4, inset). The experiment confirmed the results from the mixed-gas isotherm (cf. Section 2.1) and the breakthrough experiments reported in our previous paper showing a higher retention for ethane in line with the single component isotherms [4]. Moreover, the stable separation performance of ZIF-4 for an extended period of time is shown, viz. over 36.5 cycles and $50 \mathrm{~h}$.

In the insert, the switch between both columns is pictured by the concentration drop of ethene. The relative concentration of each peak is related to the degree of dilution by the purge gas nitrogen. By neglecting the amount of nitrogen in the product, the purity of ethene amounts to $99.16 \%$. This renders ZIF-4 as beneficial adsorbents for continuous ethene purification in order to obtain a high level of purity. With the low operation temperature and no need to employ high pressure, the running costs are expected to be low. Therefore, the utilization of ZIF-4 in PSA systems seems to be an economic alternative to ethene purification by low temperature distillation.

\subsection{Continuous Separation of Propane/Propene with MMMs}

The characterization of the applied MMMs regarding the layer thickness and the embedding of the ZIF-4 and ZIF-zni crystals was performed with a scanning electron microscope. The SEM pictures of the MMM cross sections in low and higher magnification are shown in Figure 5.
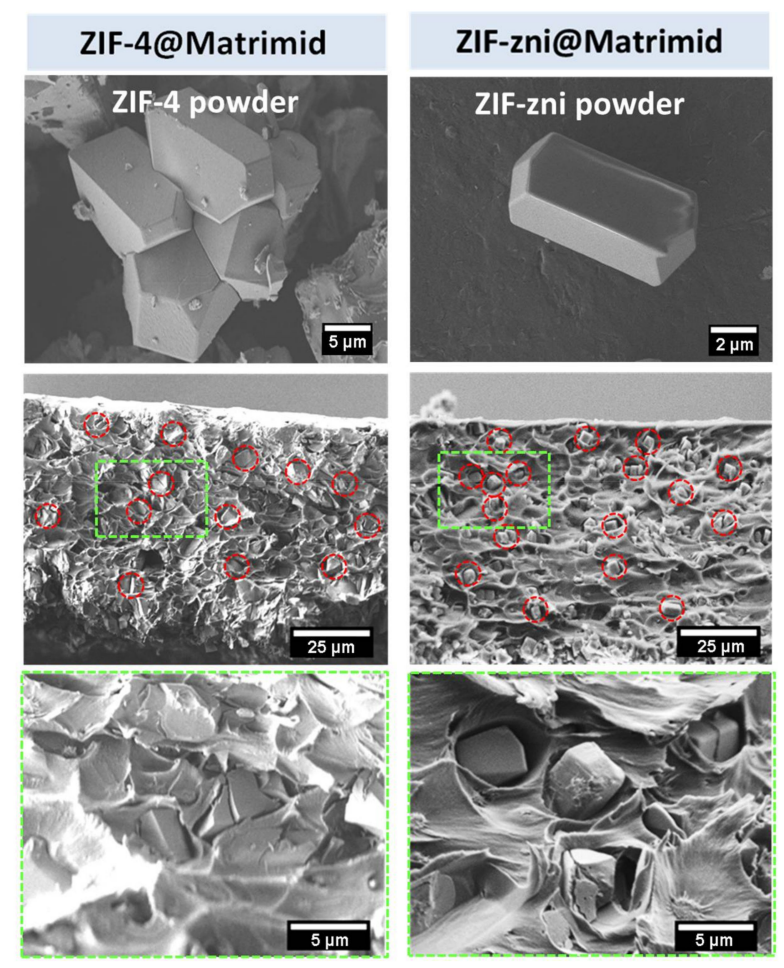

Figure 5. SEM pictures of exemplary MMMs with $10 \mathrm{wt} \%$ ZIF-4 (left) and ZIF-zni (right). Top images show the used powder materials for MMM preparation. Both pictures in the middle are cross sections of the above-mentioned MMMs, which indicate homogeneous distributed filler particles (red circles). Green squares display enlarged areas, shown at the bottom.

The images in Figure 5 imply a homogeneous distribution of the crystals in the Matrimid polymer matrix. The crystals seem to be surrounded by voids rather than directly connected to the Matrimid, especially the ZIF-zni particles. These voids may be the result of the preparation for the SEM measurements (breaking) or weak interactions between ZIF-zni and Matrimid as a consequence 
of a certain incompatibility between the filler and the matrix. The ZIF-4 crystals seem to feature better contact with the Matrimid polymer. Consequently, we expect differences with respect to the gas separation capabilities between the two composite materials not only because of their different porosity but also as a result of their different compatibility with the surrounding polymer. Nevertheless, the SEM results look promising for gas separation measurements with the corresponding MMMs. The detected thickness of the ZIF-4 membrane is $77 \mu \mathrm{m}$, while $108 \mu \mathrm{m}$ are measured for the ZIF-zni membrane. Both ZIFs are embedded in the polymer matrix as evident from their characteristic diffraction lines. Furthermore, the amorphous fraction of the used polymer Matrimid is visible as a smooth bump between 10 and $15^{\circ}$ (see Figure 6).
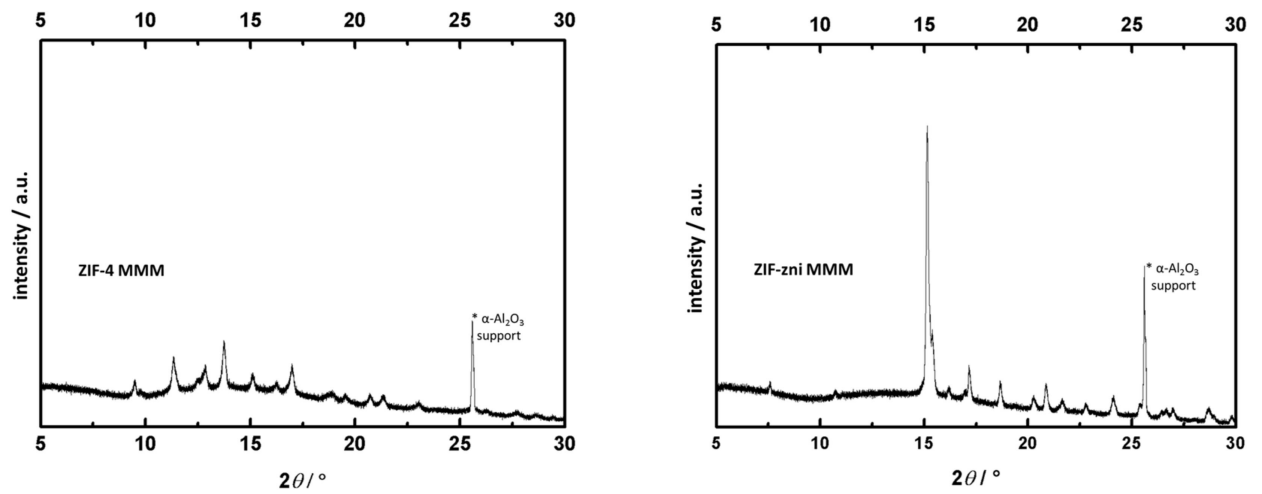

Figure 6. X-ray diffraction patterns of the two different filler based MMMs. (left) ZIF-4 particles and (right) ZIF-zni particles both embedded in Matrimid.

A feed mixture of propane and propene was used to investigate the influence of the porous adsorbents ZIF-4 and ZIF-zni as filler in MMMs in comparison to the neat polymer material Matrimid. The measured permeability as well as the calculated separation factor $(\alpha$ propene/propane $)$ for both gases on MMMs with ZIF-4, ZIF-zni and neat Matrimid is displayed in Figure 7.
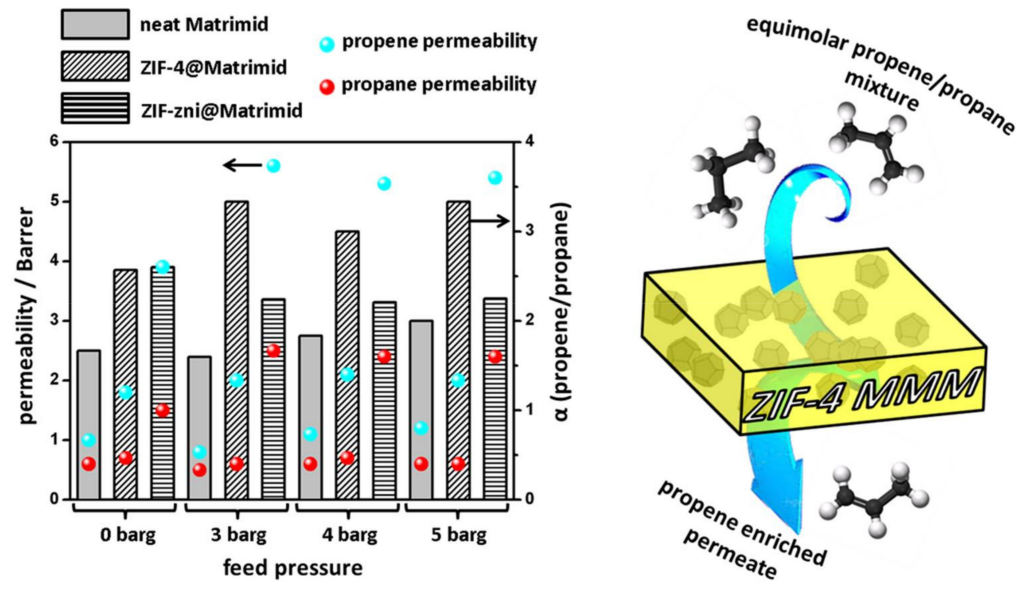

Figure 7. Mixed gas permeabilities for propene and propane as well as separation factors for two MMMs with porous materials (ZIF-4 and ZIF-zni) compared to a neat Matrimid membrane measured at $150{ }^{\circ} \mathrm{C}$ (left). Schematic demonstration of a separation process with an MMM (right).

For porous materials assembled in MMMs, the mixed gas permeabilities as well as the separation factor is generally higher compared to the neat Matrimid. The neat Matrimid membrane shows selectivities around 1.5 and propene permeabilities around 1 Barrer at 0 barg. With increasing feed pressure, both remain more or less constant. By embedding porous ZIF- 4 crystals in the Matrimid 
matrix, the separation performance of the neat polymer is drastically increased, especially at higher feed pressures ( $3-5 \mathrm{barg}$ ). Under these conditions, both the propene permeability and the separation factor are almost doubled in comparison with the neat Matrimid. When adding the denser phase ZIF-zni, the separation factor is slightly enhanced in comparison to the neat Matrimid ( 1.5 to $\approx 2.3$ ). In contrary to this, the propene permeability is almost six times higher compared to the neat polymer film. These high permeabilities are most likely a consequence of the void-rich ZIF-zni MMM, since the contact between the filler and the polymer phase is weak. The permeation results are in complete accordance with the SEM results in Figure 7. For the same reason, the separation factor is nearly the same compared to the neat Matrimid membrane, because ZIF-zni barely contributes to the separation capabilities.

\section{Experimental Section}

\subsection{Porous Adsorbents}

\subsubsection{ZIF-4}

ZIF-4 was synthesized as described elsewhere [4]. In a typical synthesis, $7.2 \mathrm{~g}$ of zinc nitrate hexahydrate (Sigma-Aldrich, Steinheim, Germany, purity 98\%) and $4.8 \mathrm{~g}$ of imidazole (Acros Organics, NJ, USA, purity $99.5 \%$ ) were dissolved in $240 \mathrm{~mL}$ of dimethylformamide (Honeywell, Seelze, Germany, purity $98-99 \%$ ), heated up to $130{ }^{\circ} \mathrm{C}$ and stirred for $48 \mathrm{~h}$.

\subsubsection{ZIF-Zni}

The synthesis for ZIF-zni is based on the pathway of Bennett et al. [38] with small modifications developed in our laboratory. Therefore, $0.67 \mathrm{~g}$ of zinc nitrate hexahydrate (Alfa Aesar, Karlsruhe, Germany, purity $99 \%$ ) and $0.5 \mathrm{~g}$ of imidazole (Sigma Aldrich, Steinheim, Germany, purity $\geq 99.5 \%$ ) were each dissolved in $50 \mathrm{~mL}$ of methanol (Sigma Aldrich, Steinheim, Germany, purity $\geq 99.8 \%$ ). Additionally, both solutions were mixed together under brief stirring in a Schott flask, followed by a rest period overnight and a heating period at $100{ }^{\circ} \mathrm{C}$ for $7 \mathrm{~h}$. After completion of the synthesis, two cooling procedures are applied, viz. at room temperature and by an ice bath. Both materials are washed twice with methanol and dried at $70{ }^{\circ} \mathrm{C}$ in an oven.

\subsection{Mixed Matrix Membranes}

Prior to the preparation of the mixed matrix membranes, the required ZIF-4 and ZIF-zni crystals were synthesized as described in Section 3.1. After synthesis, the powder materials were activated in a vacuum oven at $100{ }^{\circ} \mathrm{C}$ and 50 mbar overnight. For the preparation of the MMMs, $10 \mathrm{mg}$ of the obtained crystals were suspended with $90 \mathrm{mg}$ of Matrimid 5218 US (Huntsman, The Woodlands, TX, USA) in $1 \mathrm{ml}$ of dichloromethane (DCM) (Sigma Aldrich, purity $\geq 99.9 \%$ ) under stirring overnight. The preparation was done inside a glove box to ensure inert gas atmosphere. The dispersion was first thickened to $400 \mu \mathrm{L}$ under inert nitrogen gas atmosphere and then cast onto a porous $\alpha-\mathrm{Al}_{2} \mathrm{O}_{3}$ support with a pore diameter of $1.8 \mu \mathrm{m}$. The hardening procedure occurs under a DCM atmosphere. After evaporation of the solvent in Petri dishes, the MMMs were activated in the measurement cell at $150{ }^{\circ} \mathrm{C}$ and under a nitrogen flow to remove residual solvent (usually $24 \mathrm{~h}$ under a constant nitrogen flow). For pictures of cross sections by scanning electron microscopy (JSM-6700F from JEOL, Tokyo, Japan), the MMMs were broken into two pieces and fixed on a brass support with carbon pads. Subsequently, they were sputtered with carbon for electric conductivity.

\subsection{Apparatus for High-Pressure and Mixed Isotherms}

The pure gas equilibrium isotherms of ethane and ethene at $20{ }^{\circ} \mathrm{C}$ were measured with a gravimetric-magnetic suspension balance (MSB) from Rubotherm, Bochum, Germany (resolution $10 \mu \mathrm{g}$ ). For the measurements, $0.3 \mathrm{~g}$ of ZIF-4 were activated at $200{ }^{\circ} \mathrm{C}$ for at least $12 \mathrm{~h}$ in vacuum. The respective gas was dosed into the sample chamber. The weight as well as the gas pressure 
was recorded. The equilibrium state was assumed when the weight change was $<10 \mu g$ and pressure was constant for $10 \mathrm{~min}$. For further measurement points, the gas pressure was stepwise elevated.

For the mixed gas equilibrium isotherm, a manometric-gravimetric setup was employed. This is assembled by an MSB, which is integrated in a manometric setup (see Figure 8).

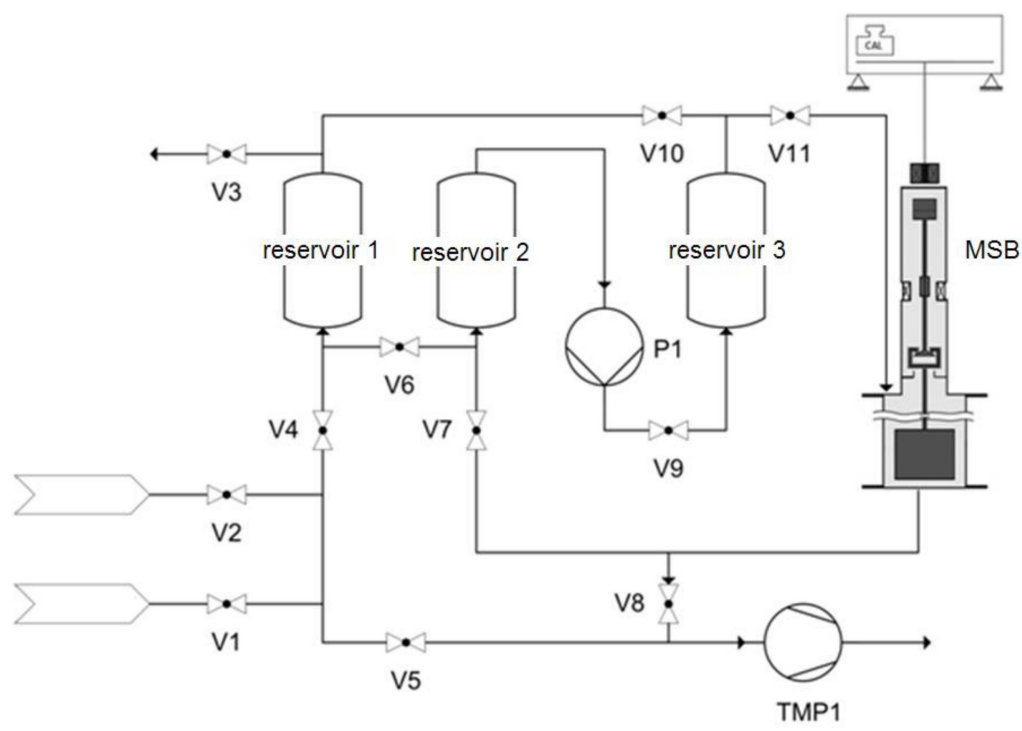

Figure 8. Schematic view of a manometric-gravimetric adsorption setup.

The gas phase composition that is necessary for balancing the manometry was analyzed with the gas chromatograph HP5890 series II from Hewlett-Packard equipped with a flame ionization detector (FID). For the measurement, ethane was first submitted to the measuring chamber until equilibrium (weight change $<10 \mu \mathrm{g}$ and constant pressure for $10 \mathrm{~min}$ ) was reached at $100 \mathrm{kPa}$. Subsequently, portions of ethene were dosed stepwise at $100 \mathrm{kPa}$ total pressure to reduce the amount of ethane in the gas phase and to enforce a partial desorption of ethane from ZIF-4. The equilibrium of the mixed gases has been calculated from the mass balance given by pairs of pressure, temperature, gas phase composition, and loading before and after the dosing of ethene to the measuring chamber. For mixed gas adsorption measurements, an amount of $1.5 \mathrm{~g}$ of activated ZIF- 4 was used.

The selectivity was calculated from experimental data (cf. Figure 2) by using the following equation:

$$
\text { equilibrium selectivity } \propto=\frac{\left(\frac{x_{1}}{y_{1}}\right)}{\left(\frac{x_{2}}{y_{2}}\right)} 1=\text { ethane and } 2=\text { ethane. }
$$

The selectivity for activated carbons and zeolites are estimated from a set of experimental data taken from the literature using the same equation. We have added this information to the experimental section.

\subsection{The Pressure Swing Adsorption Setup}

For the continuous separation of ethane and ethene mixtures, the lab scale pressure swing adsorption setup PSA-300LC from L\&C Science and Technology, Hialeah, FL, USA) was used. A thermostat with Peltier element was employed to keep a constant temperature of $20{ }^{\circ} \mathrm{C}$ in both adsorber columns (Figure 9). 


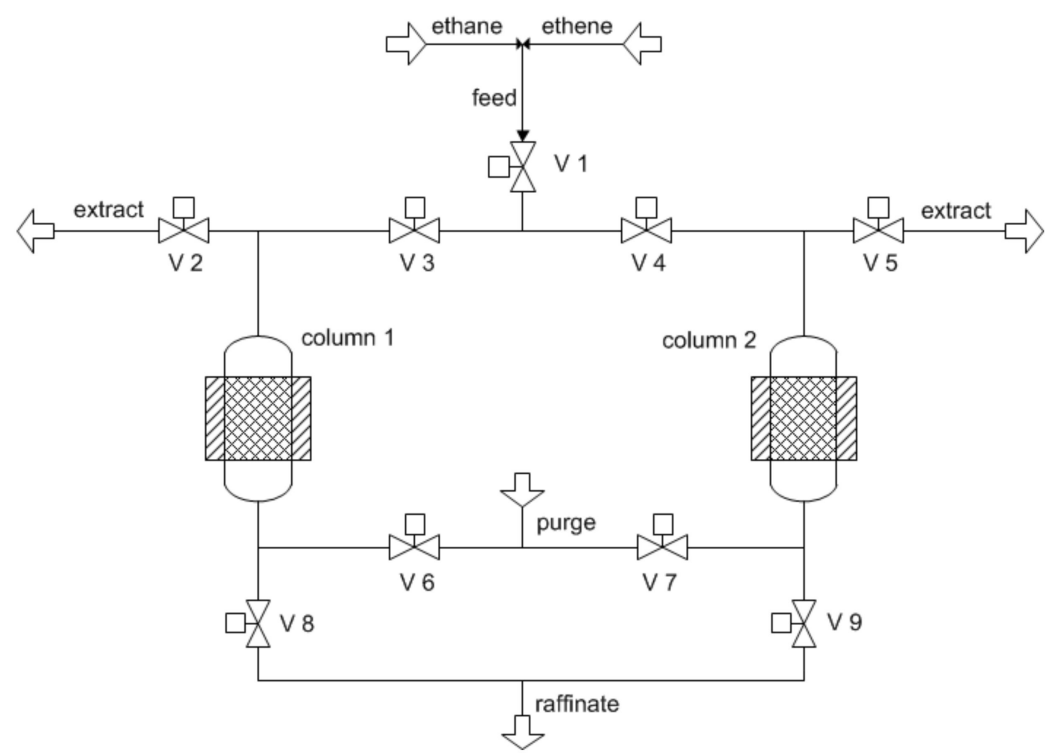

Figure 9. Simplified schematic view of the applied two-bed pressure swing adsorption (PSA) setup.

These are filled with $1.164 \mathrm{~g}$ (column 1) and $1.188 \mathrm{~g}$ (column 2) of ZIF-4 with a particle size between 106 and $250 \mu \mathrm{m}$. Both packings were ex situ activated in a vacuum oven at $150{ }^{\circ} \mathrm{C}$ for $20 \mathrm{~h}$. The inner volume of one column is ca. $2.21 \mathrm{~cm}^{3}$. For continuous separation, an operation mode similar to the Skarstrom cycle $[39,40]$ was used. The experiments were conducted at ambient feed pressure, no pressurization or blowdown step was necessary.

One cycle consists of the adsorption and purging step of the first column and the purging and adsorption step of the second column. The adsorption step of the first column runs parallel to the purging step of the second column. This cycle can be repeated ad libitum and defines the length of the separation experiment.

The feed $\left(V_{\text {feed }}=2 \mathrm{~mL}_{\mathrm{N}} / \mathrm{min}\right)$, an equimolar mixture of ethane and ethene, is loaded and separated during the adsorption step. For the purging step, nitrogen $\left(V_{\text {purge }}=150 \mathrm{~mL} / \mathrm{min}\right)$ was used to regenerate the loaded column in counter current to the feed.

By purging with a third gas and running the process at ambient pressure, this mode of operation is sometimes rather called concentration swing adsorption (CSA). This expression is related to the process described by Rao et al. for separating azeotropic liquid mixtures where a third component was used for purging [41]. The cycle time is $82 \mathrm{~min}$, which is the sum of the separation times for both columns, viz. $40 \mathrm{~min}$ for Column 1 and $42 \mathrm{~min}$ for Column 2 . The different adsorption intervals are related to the different batting of the columns. The time of the adsorption step is determined from mixed breakthrough experiments for each column. The applied separation time is related to the breakthrough times of ethane. For downstream analysis of the gas mixture at the adsorber outlet, a gas chromatograph GC-456 Scion from Bruker equipped with an FID was employed.

\subsection{Membrane Setup}

For the permeation measurements, a home-built apparatus (displayed in Figure 10) based on the idea of Wicke Kallenbach was used. An equimolar mixture of propane and propene $\left(\dot{V}_{\text {feed }}=60 \mathrm{~mL}_{\mathrm{N}} / \mathrm{min}\right)$ is transported to the membrane in the permeation cell. The molecules passing the membrane are called permeate and the retained molecules leave the permeation cell as retentate. To preserve a high driving force and to enable analysis, the permeate is swept with nitrogen $\left(V_{\text {sweep }}=1 \mathrm{~mL}_{\mathrm{N}} / \mathrm{min}\right)$ toward a gas chromatograph (Agilent Technologies 7890 B, Waldbronn, Germany). The permeation experiment was carried out at a constant temperature of $150{ }^{\circ} \mathrm{C}$ and at different feed pressures $(0 \mathrm{barg}, 3 \mathrm{barg}, 4 \mathrm{barg}$, 
and 5 barg). Measurements were carried out until the equilibrium was reached, which was usually achieved after $24 \mathrm{~h}$ of continuous testing.

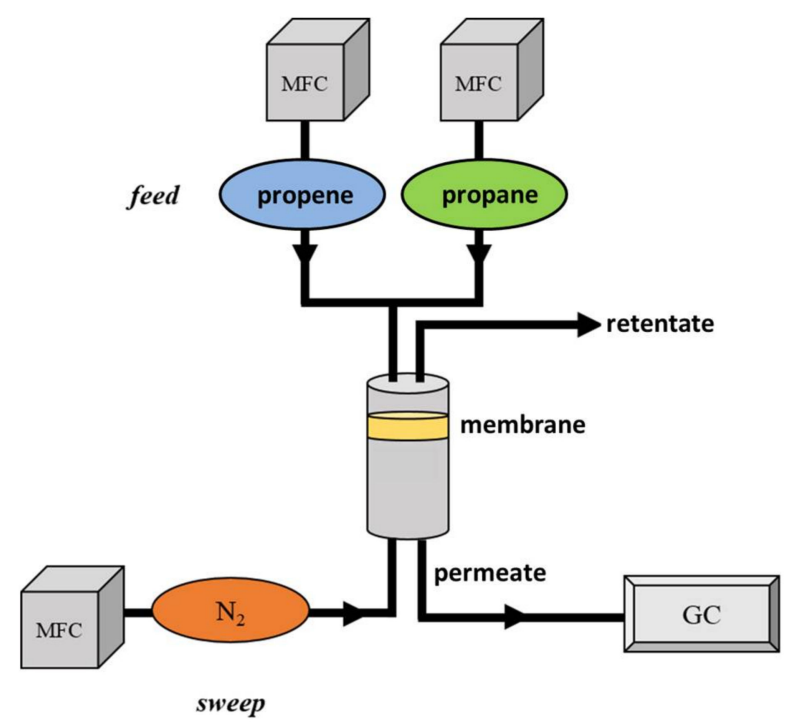

Figure 10. Schematic view of the experimental setup according to Wicke Kallenbach used for permeation measurements with mixed matrix membranes (MMMs) and binary propane/propene mixtures.

\section{Conclusions}

The sorption and separation potential of ZIF-4 powder as well as ZIF-4 and ZIF-zni crystals embedded in Matrimid membranes were studied regarding paraffin and olefin separation using different experimental techniques, in particular gravimetry-manometry, pressure swing adsorption, and membrane permeation.

Adsorption isotherms of ethane and ethene at $20^{\circ} \mathrm{C}$ showed a higher loading of ethane compared to ethene in the low pressure range, which results in a higher retention of unwanted ethane. For higher pressure $(>200 \mathrm{kPa})$, the separation performance is reduced due to the smaller difference in loading for both gases. Finally, the loading of ethene exceeds the values of ethane, which implies a higher retention of the requested gas and is adverse for its purification.

The mixed isotherms for ethane and ethene showed ideal behavior, which allows to predict further equilibrium data for mixtures with ideal adsorption solution theory based on pure component isotherms.

The continuous separation of equimolar ethane/ethene mixtures was successfully demonstrated with ZIF-4 powder in the lab scale pressure swing adsorption setup. Over a specific period of $50 \mathrm{~h}$, the separation performance does not decline, which is related to the stable adsorption behavior of ZIF-4 and the proper regeneration during the purging step. Therefore, the separation is more influenced by static adsorption than kinetic effects.

The embedding of ZIF-4 and ZIF-zni crystals in the polymer matrix Matrimid was successful and showed beneficial properties of the resulting MMM with respect to the permeability of propane and propene compared to the neat Matrimid membrane. The best separation factor of propane and propene was achieved with ZIF-4 crystals in MMMs that doubled the value of the neat Matrimid. Separation capabilities might be further improved in future studies by increasing the interaction between the filler and the matrix. 
Acknowledgments: Financial support for this work by the German Science Foundation (Deutsche Forschungsgemeinschaft, DFG) in the frame of the priority program SPP 1570 under contract HA 2527/12-3 is gratefully acknowledged. The authors of this work are also grateful for the financial support from the EU 7th Framework Project $\mathrm{M}^{4} \mathrm{CO}_{2}$ (Grant Agreement No 608490), organized by Freek Kapteijn and Jorge Gascon. We also thank Jürgen Caro for stimulating discussions.

Author Contributions: Maximilian Hovestadt synthesized the ZIF-4 powder and performed the PSA measurements. Marcus Lange and Jens Möllmer measured the high pressure single component isotherms and the mixed adsorption equilibria for ethane and ethene. Alexander Mundstock prepared ZIF-4 and ZIF-zni crystals for membrane embedding. Lailah Helmich prepared and tested the mixed-matrix membranes. Sebastian Friebe characterized the MMMs by XRD and SEM and contributed to the interpretation of the membrane-based separation. Roger Gläser and Martin Hartmann supervised the study. All authors discussed the results and participated in writing the manuscript.

Conflicts of Interest: The authors declare no conflict of interest.

\section{References}

1. Hartman, M.; Kunz, S.; Himsl, D.; Tangermann, O.; Wagener, A.; Ernst, S. Adsorptive Separation of Isobutene and Isobutane on $\mathrm{Cu}_{3}(\mathrm{BTC})_{2}$. Langmuir 2013, 24, 8634-8642. [CrossRef] [PubMed]

2. Bendt, S.; Hovestadt, M.; Böhme, U.; Paula, C.; Döpken, M.; Hartmann, M.; Keil, F.J. Olefin/Paraffin Separation Potential of ZIF-9 and ZIF-71: A Combined Experimental and Theoretical Study. Eur. J. Inorg. Chem. 2016, 2016, 4440-4449. [CrossRef]

3. Hovestadt, M.; Bendt, S.; Mondal, S.S.; Behrens, K.; Reif, F.; Döpken, M.; Holdt, H.-J.; Keil, F.J.; Hartmann, M. Experimental and theoretical analysis of the influence of different linker molecules in Imidazolate Frameworks Potsdam (IFP-n) on the separation of olefin-paraffin mixtures. Langmuir 2017, 33, 11170-11179. [CrossRef] [PubMed]

4. Hartmann, M.; Böhme, U.; Hovestadt, M.; Paula, C. Adsorptive Separation of Olefin/Paraffin Mixtures with ZIF-4. Langmuir 2015, 31, 12382-12389. [CrossRef] [PubMed]

5. Narin, G.; Martins, V.F.D.; Campo, M.; Ribeiro, A.M.; Ferreira, A.; Santos, J.C.; Schumann, K.; Rodrigues, A.E. Light olefins/paraffins separation with 13X zeolite binderless beads. Sep. Purif. Technol. 2014, 133, 452-475. [CrossRef]

6. Geier, S.J.; Mason, J.A.; Bloch, E.D.; Queen, W.L.; Hudson, M.R.; Brown, C.M.; Long, J.R. Selective adsorption of ethylene over ethane and propylene over propane in the metal-organic frameworks $\mathrm{M} 2$ (dobdc) $(\mathrm{M}=\mathrm{Mg}$, Mn, Fe, Co., Ni, Zn). Chem. Sci. 2013, 4, 2054-2061. [CrossRef]

7. Böhme, U.; Barth, B.; Paula, C.; Kuhnt, A.; Schwieger, W.; Mundstock, A.; Caro, J.; Hartmann, M. Ethene/Ethane and Propene/Propane Separation via the Olefin and Paraffin Selective Metal-Organic Framework Adsorbents CPO-27 and ZIF-8. Langmuir 2013, 29, 8592-8600. [CrossRef] [PubMed]

8. Plaza, M.G.; Ferreira, A.F.P.; Santos, J.C.; Ribeiro, A.M.; Müller, U.; Trukhan, N.; Loureiro, J.M.; Rodrigues, A.E. Propane/propylene separation by adsorption using shaped copper trimesate MOF. Microporous Mesoporous Mater. 2012, 157, 101-111. [CrossRef]

9. Dewar, J. A review of the pi-complex theory. Bull. Soc. Chim. Fr. 1951, 18, C71-C79.

10. Chatt, J.; Duncanson, L.A. 586. Olefin co-ordination compounds. Part III. Infra-red spectra and structure: Attempted preparation of acetylene complexes. J. Chem. Soc. (Resumed) 1953, 2939-2947. [CrossRef]

11. Gucuyener, C.; van den Bergh, J.; Gascon, J.; Kapteijn, F. Ethane/Ethene Separation Turned on Its Head: Selective Ethane Adsorption on the Metal-Organic Framework ZIF-7 through a Gate-Opening Mechanism. J. Am. Chem. Soc. 2010, 132, 17704-17706. [CrossRef] [PubMed]

12. Fu, H.-R.; Wang, F.; Zhang, J. A stable zinc-4-carboxypyrazole framework with high uptake and selectivity of light hydrocarbons. Dalton Trans. 2015, 44, 2893-2896. [CrossRef] [PubMed]

13. He, Y.; Song, C.; Ling, Y.; Wu, C.; Krishna, R.; Chen, B. A new MOF-5 homologue for selective separation of methane from $\mathrm{C}_{2}$ hydrocarbons at room temperature. APL Mater. 2014, 2, 124102. [CrossRef]

14. Chen, Y.; Qiao, Z.; Wu, H.; Lv, D.; Shi, R.; Xia, Q.; Zhou, J.; Li, Z. An ethane-trapping MOF PCN-250 for highly selective adsorption of ethane over ethylene. Chem. Eng. Sci. 2018, 175, 110-117. [CrossRef]

15. Liang, W.; Zhang, Y.; Wang, X.; Wu, Y.; Zhou, X.; Xiao, J.; Li, Y.; Wang, H.; Li, Z. Asphalt-derived high surface area activated porous carbons for the effective adsorption separation of ethane and ethylene. Chem. Eng. Sci. 2017, 162, 192-202. [CrossRef] 
16. Jakobtorweihen, S.; Keil, F.J. Adsorption of alkanes, alkenes and their mixtures in single-walled carbon nanotubes and bundles. Mol. Simul. 2009, 35, 90-99. [CrossRef]

17. Hovestadt, M.; Schmitz, J.V.; Weissenberger, T.; Reif, F.; Kaspereit, M.; Schwieger, W.; Hartmann, M. Scale-up of the Synthesis of Zeolitic Imidazolate Framework ZIF-4. Chem. Ing. Tech. 2017, 89, 1374-1378. [CrossRef]

18. Phan, A.; Doonan, C.J.; Uribe-Romo, F.J.; Knobler, C.B.; Okeeffe, M.; Yaghi, O.M. Synthesis, structure, and carbon dioxide capture properties of zeolitic imidazolate frameworks. Acc. Chem. Res. 2010, 43, 58-67. [CrossRef] [PubMed]

19. Jee, J.-G.; Kim, M.-B.; Lee, C.-H. Pressure swing adsorption processes to purify oxygen using a carbon molecular sieve. Chem. Eng. Sci. 2005, 60, 869-882. [CrossRef]

20. Shah, M.; Mondal, P.; Nayak, A.; Bordoloi, A. Hydrogen from Natural Gas. In Sustainable Utilization of Natural Resources; CRC Press: Boca Raton, FL, USA, 2017; pp. 81-120.

21. Martins, V.F.D.; Ribeiro, A.M.; Santos, J.C.; Loureiro, J.M.; Gleichmann, K.; Ferreira, A.; Rodrigues, A.E. Development of gas-phase SMB technology for light olefin/paraffin separations. AIChE J. 2016, 62, 2490-2500. [CrossRef]

22. Nandi, S.; Haldar, S.; Chakraborty, D.; Vaidhyanathan, R. Strategically designed azolyl-carboxylate MOFs for potential humid $\mathrm{CO}_{2}$ capture. J. Mater. Chem. A 2017, 5, 535-543. [CrossRef]

23. Friebe, S.; Mundstock, A.; Unruh, D.; Renz, F.; Caro, J. NH2-MIL-125 as membrane for carbon dioxide sequestration: Thin supported MOF layers contra Mixed-Matrix-Membranes. J. Membr. Sci. 2016, 516, 185-193. [CrossRef]

24. Pan, Y.; Li, T.; Lestari, G.; Lai, Z. Effective separation of propylene/propane binary mixtures by ZIF-8 membranes. J. Membr. Sci. 2012, 390, 93-98. [CrossRef]

25. Mundstock, A.; Wang, N.; Friebe, S.; Caro, J. Propane/propene permeation through Na-X membranes: The interplay of separation performance and pre-synthetic support functionalization. Microporous Mesoporous Mater. 2015, 215, 20-28. [CrossRef]

26. Bhave, R.; Kuritz, T.; Powell, L.; Adcock, D. Membrane-Based Energy Efficient Dewatering of Microalgae in Biofuels Production and Recovery of Value Added Co-Products. Environ. Sci. Technol. 2012, 46, 5599-5606. [CrossRef] [PubMed]

27. Merkel, T.C.; Bondar, V.I.; Nagai, K.; Freeman, B.D.; Pinnau, I. Gas sorption, diffusion, and permeation in poly(dimethylsiloxane). J. Polym. Sci. Part B Polym. Phys. 2000, 38, 415-434. [CrossRef]

28. Dechnik, J.; Gascon, J.; Doonan, C.J.; Janiak, C.; Sumby, C.J. Mixed-Matrix Membranes. Angew. Chem. Int. Ed. 2017, 56, 9292-9310. [CrossRef] [PubMed]

29. Seoane, B.; Coronas, J.; Gascon, I.; Benavides, M.E.; Karvan, O.; Caro, J.; Kapteijn, F.; Gascon, J. Metal-organic framework based mixed matrix membranes: A solution for highly efficient $\mathrm{CO}_{2}$ capture? Chem. Soc. Rev. 2015, 44, 2421-2454. [CrossRef] [PubMed]

30. Zhang, Y.; Feng, X.; Yuan, S.; Zhou, J.; Wang, B. Challenges and recent advances in MOF-polymer composite membranes for gas separation. Inorg. Chem. Front. 2016, 3, 896-909. [CrossRef]

31. Galizia, M.; Chi, W.S.; Smith, Z.P.; Merkel, T.C.; Baker, R.W.; Freeman, B.D. 50th Anniversary Perspective: Polymers and Mixed Matrix Membranes for Gas and Vapor Separation: A Review and Prospective Opportunities. Macromolecules 2017, 50, 7809-7843. [CrossRef]

32. Thommes, M.; Kaneko, K.; Alexander, V.N.; James, P.O.; Rodriguez-Reinoso, F.; Rouquerol, J.; Kenneth, S.W.S. Physisorption of gases, with special reference to the evaluation of surface area and pore size distribution (IUPAC Technical Report). In Pure and Applied Chemistry; IUPAC Blackwell Science: Research Triangle Park, NC, USA, 2015; Volume 87, p. 1051.

33. Reich, R.; Ziegler, W.T.; Rogers, K.A. Adsorption of Methane, Ethane, and Ethylene Gases and Their Binary and Ternary Mixtures and Carbon Dioxide on Activated Carbon at 212-301 K and Pressures to 35 Atmospheres. Ind. Eng. Chem. Process Des. Dev. 1980, 19, 336-344. [CrossRef]

34. Szepesy, L.; Illes, V. Adsorption of gases and gas mixtures. III. Investigation of the adsorption equilibria of binary gas mixtures. Acta Chim. Hung. Tomus 1963, 35, 245.

35. Kaul, B.K. A modern version of volumetric apparatus for measuring gas-solid equilibrium data. Ind. Eng. Chem. Res. 1987, 26, 928-933. [CrossRef]

36. Sakurovs, R.; Day, S.; Weir, S. Relationships between the critical properties of gases and their high pressure sorption behavior on coals. Energy Fuels 2010, 24, 1781-1787. [CrossRef] 
37. Polanyi, M. Adsorption from the point of view of the Third Law of Thermodynamics. Verh. Deut. Phys. Ges. 1914, 16, 1012-1016.

38. Bennett, T.D.; Keen, D.A.; Tan, J.-C.; Barney, E.R.; Goodwin, A.L.; Cheetham, A.K. Thermal Amorphization of Zeolitic Imidazolate Frameworks. Angew. Chem. Int. Ed. 2011, 50, 3067-3071. [CrossRef] [PubMed]

39. Ruthven, D.M.; Farooq, S.; Knaebel, K.S. Pressure Swing Adsorption; VCH Publishers: Weinheim, Germany, 1994; p. 352.

40. Skarstrom, C.W. Method and Apparatus for Fractionating Gaseous Mixtures by Adsorption. Google Patents. U.S. Patent 2944627, 7 December 1960.

41. Rao, M.B.; Sircar, S. Concentration Swing Adsorption: Novel Processes for Bulk Liquid Separations. In Precision Process Technology: Perspectives for Pollution Prevention; Weijnen, M.P.C., Drinkenburg, A.A.H., Eds.; Springer: Dordrecht, The Netherlands, 1993; pp. 345-352.

Sample Availability: Samples of the compounds ZIF-4 and ZIF-zni are available from the authors.

(C) 2018 by the authors. Licensee MDPI, Basel, Switzerland. This article is an open access article distributed under the terms and conditions of the Creative Commons Attribution (CC BY) license (http://creativecommons.org/licenses/by/4.0/). 